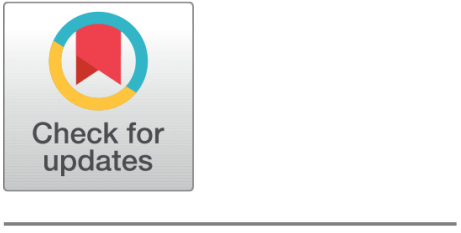

OPEN ACCESS

Received: 11.06.2021

Accepted: 28.08.2021

Published: 25.10 .2021

Citation: Katikala HB, Murthy GR, Nath YA (2021) Design and Implementation of High Performance PPSK demodulator in Biomedical Implant. Indian Journal of Science and Technology 14(34):

2742-2750. https://doi.org/

10.17485/IJST/V14i34.1071

* Corresponding author.

ramana.murthy@alliance.edu.in

Funding: None

Competing Interests: None

Copyright: ๑ 2021 Katikala et al. This is an open access article distributed under the terms of the Creative Commons Attribution License, which permits unrestricted use, distribution, and reproduction in any medium, provided the original author and source are credited.

Published By Indian Society for Education and Environment (iSee)

ISSN

Print: 0974-6846

Electronic: 0974-5645

\section{Design and Implementation of High Performance PPSK demodulator in Biomedical Implant}

\author{
Hima Bindu Katikala1 , G Ramana Murthy2 ${ }^{2}$, Yatavakilla Amarendra Nath \\ 1 Assistant Professor, Department of E.C.E, VFSTR (Deemed to be University), Vadlamudi, \\ 522213, India \\ 2 Professor, Department of E.C.E, Alliance College of Engineering and Design, Alliance \\ University, Bangalore, 562106, India \\ 3 Project Scientist, CGCRI-CSIR, Kolkata, 700032, West Bengal, India
}

\section{Abstract}

Background/Objective: The important challenge for the realization of hearing aids is small size, low cost, low power consumption, and better performance, etc. Keeping these requirements in view this work concentrates on the VLSI (Very Large Scale Integrated) implementation of the analog circuit that mimics the PPSK (Passive Phase Shift Keying) demodulator with a low pass filter. Methodology: This research deals with RF Cochlear implant circuits and their data transmission. A PPSK modulator is used for uplink data transmission in biomedical implants with simultaneous power, data transmission. This study deals with the implementation of a PPSK demodulator with related circuits and a low pass filter which are used in cochlear implants consumes low power and operates at $14 \mathrm{MHz}$ frequency. These circuits are designed using FINFET $20 \mathrm{~nm}$ technology with $0.4 \mathrm{v}$ DC supply voltage. Findings: The performance of the proposed design over the previous design is operating at low threshold voltage, reduces static leakage currents, and often observed greater than 30 times of improvement in speed performance Novelty: As the conventional design with the same supply voltage $(0.4 \mathrm{v})$ exhibit high power dissipation and delay and require more amount of time to demodulate the signal. Whereas the proposed FINFET based monostable circuit and PPSK demodulator with a low pass filter has proven better in terms of less delay and power dissipation and can transmit the data with less bit error rate in stipulated time.

Keywords: Cochlear Implant (Cl); Fin Field Effect Transistor (FINFET); Electrode Array; Back Telemetry; PPSK Demodulator

\section{Introduction}

Many wireless medical implants ${ }^{(1)}$ are specifically used for prosthesis and diagnosis, functioned to mimic regular body parts. In the field of Pharmacy, designing these implants requires miniaturization of technology \& also component scaling. In general, implants are contrived from the skin, bone, tissues \& materials-metal/plastic/ceramic, 
insertion of nanometer scaled $(\mathrm{nm})$ implant and generation of ionic potential stimulus from the injected electrode array inside the human body through these kinds of the implant is challenging task. The best HYPACUSIS treatment implant is COCHLEAR IMPLANT $(\mathrm{CI})^{(2)}$ helps to impetus the auditory nerve directly by stimulating hair cells of the EAR. However, VLSI advanced technologies like CNTFET, FINFET, and TFET makes the scaling of channel width rather than CMOS, leading to certain parametric variations (Power, Delay \& Area) accordingly. Designing of implants by incorporating mentioned technologies may enhance the productivity \& performance. This research work deals with the exploitation of COCHLEAR implant circuit designing in advanced VLSI technologies. Moore's law ${ }^{(3)}$ states for every couple of years, there is a doubling of transistor count on an integrated chip by scaling the technology as in Figure 1. Researchers' progressive efforts from past decades originated a nanometer $(\mathrm{nm})$ technology transistor known as FINFET; shorten the cons of CMOS technology. With FINFET ${ }^{(4)}$ narrow channel dual gate structure of Figure 2. Leakage current is lessened \& deepens carrier mobility: without increasing doping concentration \& require low operating voltage $(\sim 0.4 \mathrm{v})$ subsequently condense power dissipation. In evidence to WHO recent proclamation $^{(5)} 488$ million people complain of hearing disabilities for $>40 \mathrm{~dB}$ echo auditory signals \& may extent to $>900$ million by 2025 via environment conditions, noise pollution, etc., Settling to above strategy research inventors proposing certain medication facilities like artificial implantation (CI) from early 1800 to till date by accommodating electrodes for designing purpose. CI uses 22 active platinum electrodes providing 11 channels as an array, with a length of $17 \mathrm{~mm}$, each electrode isolation of $<0.1 \mathrm{~mm} \&$ facilitates the biphasic electric stimulus to the auditory nerve ${ }^{(6,7)}$ and spiral ganglion nerve in Figure 3 .

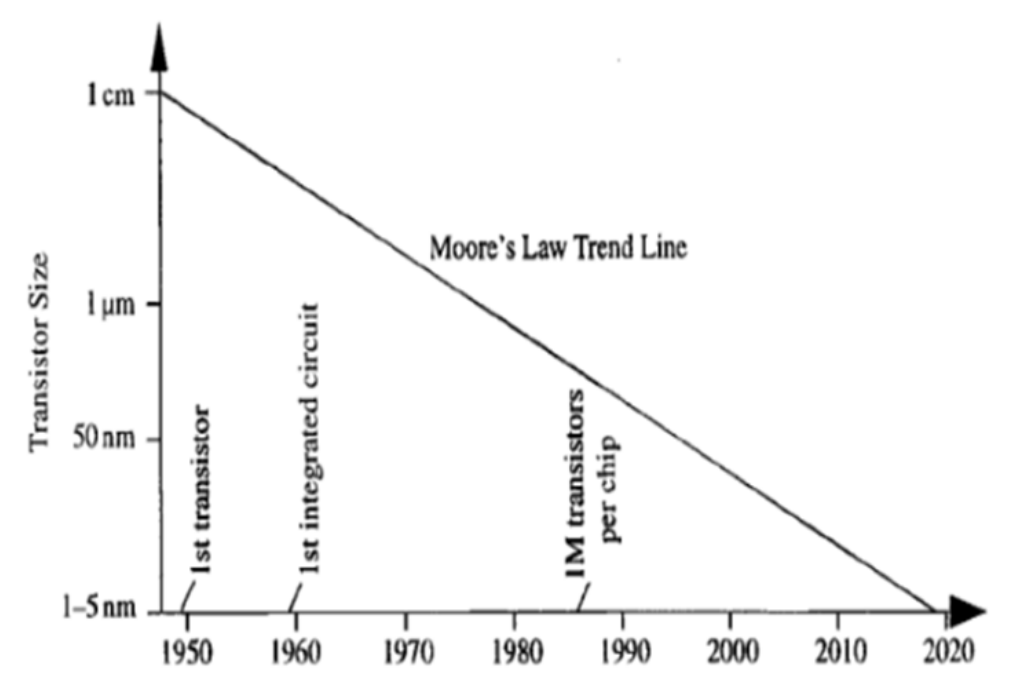

Fig 1. Transistor scaling technology

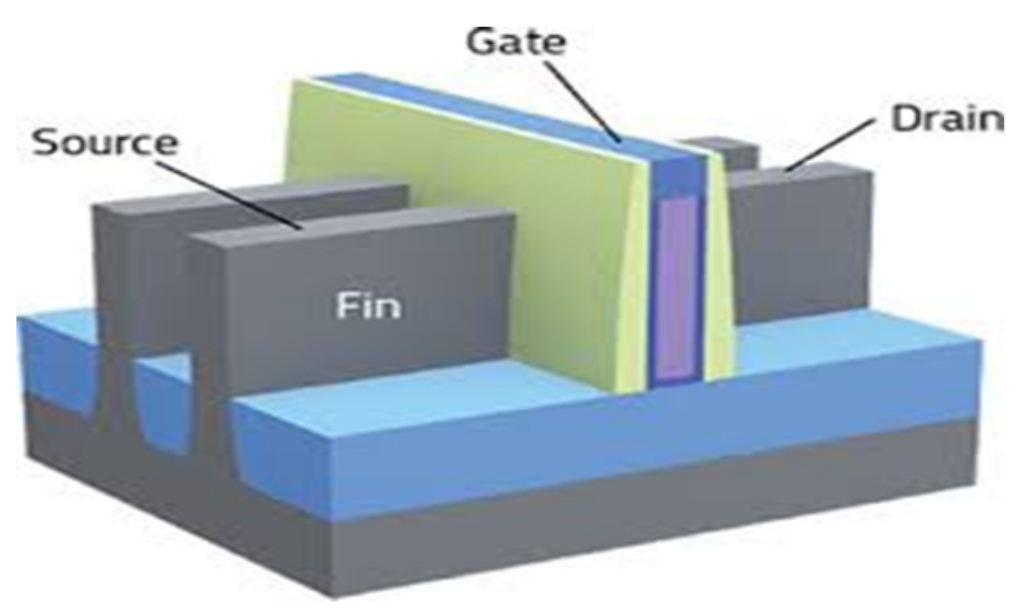

Fig 2. FINFET Planar Structure 


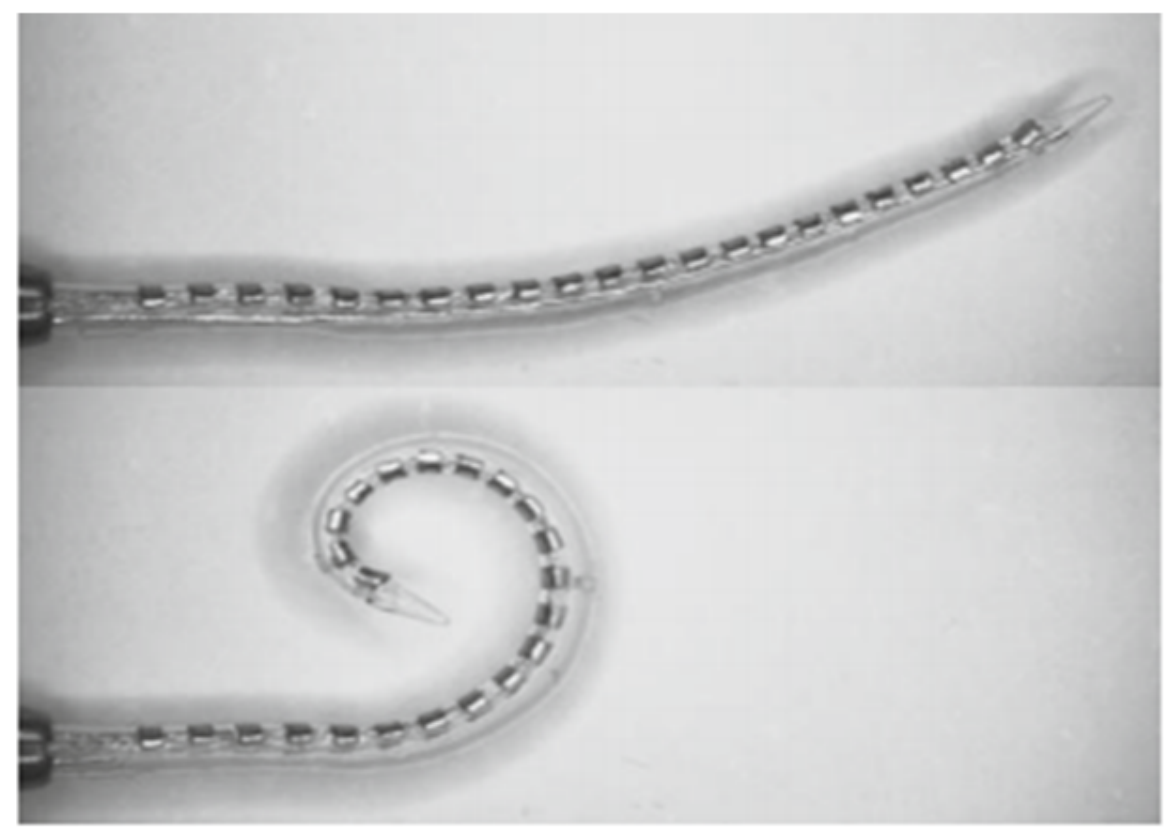

Fig 3. CI Platinum Electrode Array

Conventional CI contains internal parts: Electrode array, transmitter \& receiver /Stimulator (9.5 gm) enclosed with external parts: microphone and speech processor. Highly designed CI requires 5-6 hours of surgery for stabilizing hearing sense \& placing of Implant inside the ear. Figure 4 describes the signal processing of $\mathrm{CI}$ from internal to external parts perfectly.

1. Speech Processor-receives acoustic signals via microphone

2. Transmitter-transmits the encoded audio signals to the internal receiver

3. Electrode array-receives transmitted impulses.

4. Auditory nerve-The Electrode array electrically stimulates the auditory nerve.

Table 1 discusses the contribution of an inventor, especially about auditory Neuro-stimulus and their functionalities ${ }^{(8)}$.

Table 1. Invention Route-map of CI

\begin{tabular}{llll}
\hline Year & Inventor & Device & Application \\
\hline 1800 & Alexandra Volta & Metal rod insertion & Auditory Sensation \\
1930 & Waver- Bray & Auditory nerve connected with electrode & Sound Processing. \\
1950 & Lundeberg & Stimulate Auditory nerve using electricity & Anticipate Processing \\
1957 & Djourna and Eyeries & Stimulate Auditory with current & Perfect Auditory Purpose \\
1961 & House- Doyle & Electrodes insertion for profoundly deaf adults & Clear Auditory Response \\
1972 & Cochlear Corporation & 1stsingle channel cochlear implant development & Stimulus functionality \\
1984 & Cochlear Corporation FDA & Wearable Speech Processor "NUCLEUS" & Speech Coding Strategy \\
1989 & Cochlear corporation & Mini Speech Processor (MSP) & Small size made it suitable for chil- \\
& & & dren \\
2006 & Ronald & Advanced Electrolyte Stylet (AOS) & Multi-channel Speech Processor. \\
\hline
\end{tabular}




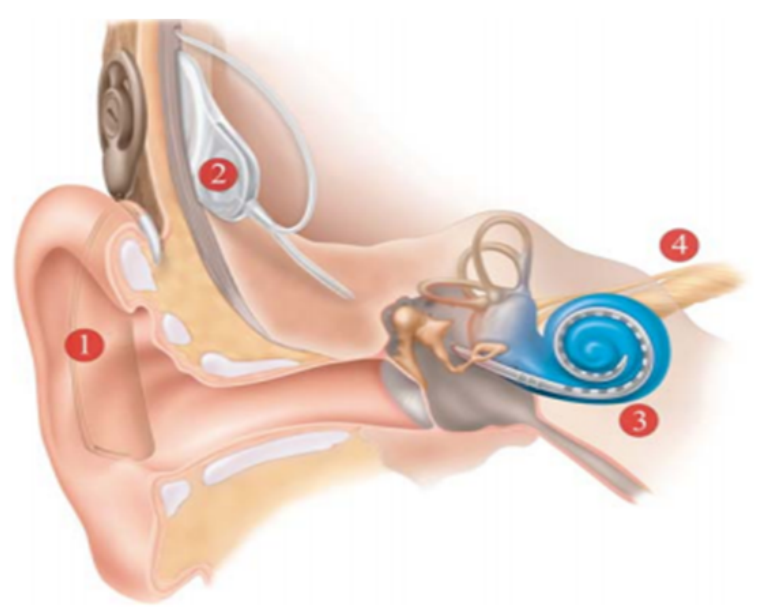

Fig 4. CI Signal Processing

\section{FINFET trends in COCHLEAR IMPLANT (Cl).}

The scope of the electronics in CI is to design the functioning circuits like speech processor, transmitter, etc., by using VLSI technology. The signal processing of the external source to the internal part of the ear is perfectly prototype in Figure $5^{(9)}$. Modern CI can be successfully progressed by applying a proper synchronized clock implemented in FINFET topology ${ }^{(10)}$ that is in Radio Frequency (RF) range. All the medical devices are driven mostly in RF range for ensuring safety interconnect between internal and external parts, to transmit both power and data. The Major sub block is Back telemetry to pretend to monitor the internal unit, electrode unit conditions \& neural responses. An ASIC chip with power amplifier ${ }^{(11)}$, error frees decoder/demodulator ${ }^{(12)}$ and Analog to Digital Converter (ADC) is integrated for internal feedback purpose. However, propagating the signal impulse in move range into the body is crucial task.

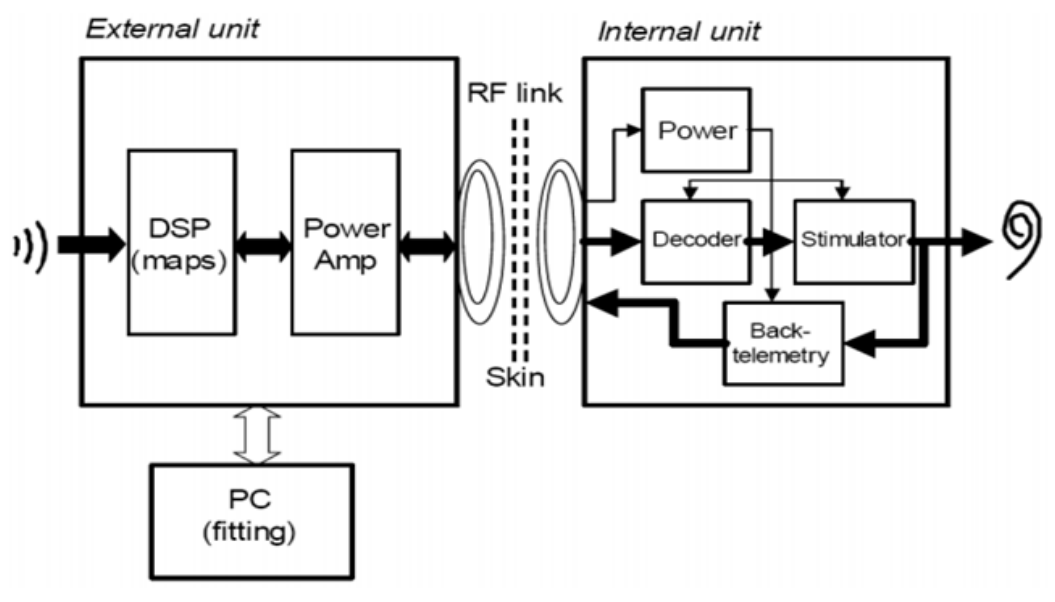

Fig 5. Modern CI Functional Block Diagram.

From the Era of Telephone by Graham Bell in the $18^{\text {th }}$ century, Electrophonic Perception of Stevens with his colleagues in the $19^{\text {th }}$ century, William's Gold Electrode implantable chip in the mid of $19^{\text {th }}$ century proven the audio-signal stimulates in deaf patients \& prearranged the trail invention of hearing-aid implantable devices. Various implantable integrated analog circuits have been designed for numerous clinical applications such as cardiac pacemakers, cochlear implants, retinal prostheses, and functional neuromuscular stimulation (FNS) systems. These devices are active implants that require energy sources like solar, infrared \& wireless energy transfer for functioning ${ }^{(13)}$. In implanted system, power ${ }^{(14,15)}$ is the major concern in the 
system design. Due to the lifetime limitation, the battery is not the optimal choice in the implanted device. In recent years, electromagnetic propagation through inductive coupling links is widely used to deliver power and information to these implantable systems.

These approaches can avoid the risk of causing infection and battery life problems. In general, implantable systems must satisfy the following requirements: 1) long-lifetime, 2) high reliability and 3) small size. The implanted device (bio-devices) senses the internal data (body) and converse with the external world by means of power and telemetry ${ }^{(16,17)}$ hence biotelemetry link is used as the bidirectional transmission between bio-device and external tools. The process of data transmission between the bio-device and the tool is in the form of uplink and downlink. Sending of data from the implant to the external world is known as DOWNLINK and its inverse is termed as UPLINK. Bio-device consists of a sensor and a stimulator. The biosignals are sensed by the sensor and the sensed data is transmitted to the doctors for diagnosis. Multi Stimulator ${ }^{(18)}$ acts as a feedback element that tracks the status of the nerves and the implant. Taking it as a challenge the parts of implantable devices are designed the CMOS technology by considering all technical parametric issues ${ }^{(19)}$. The main characteristic of an implant is, to modulate the data within the load impedance ${ }^{(20,21)}$ of the inductive link otherwise the increased modulation index decreases the data rate hence the transfer power efficiency decreases ${ }^{(22)}$. For better modulation, a PPSK demodulator is designed with FINFET technology and compared with existing technology. Based on the considerations, an analog PPSK demodulator communication module circuit is proposed in FINFET technology, because of its low doping concentration with good matching \& better performance through proper voltage biasing.

\subsection{Conventional PPSK Demodulator}

The telemetry circuit implemented in CMOS technology for cochlear implants is shown in Figure 6. It is a surgical device, which senses audio signals from a hearing-impaired person. The device consists of a microphone placed outside the ear and an electrode array in the inner ear and the skin acts as an inductive link between the external and internal parts of the ear. Injecting the device in the exact position of the body takes 6 hours of surgery; however, it should be miniaturized and consume less power.

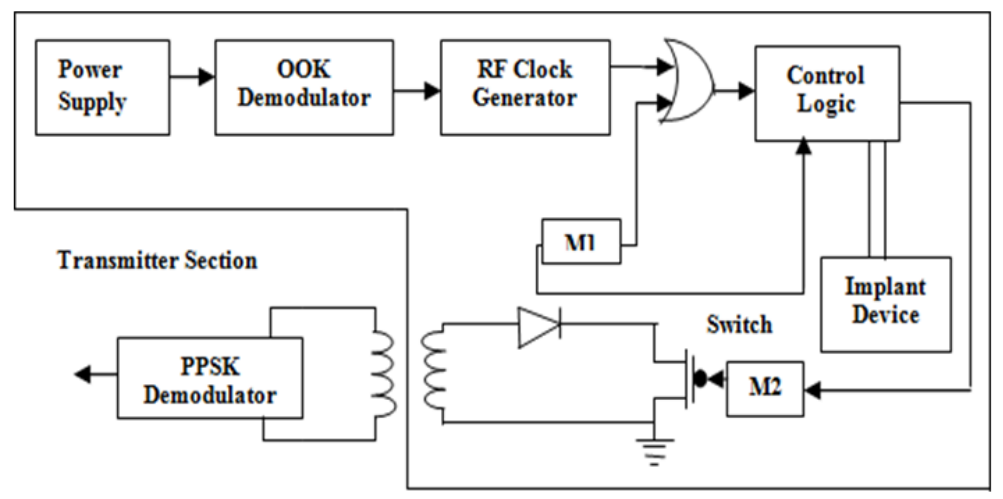

Fig 6. Telemetry Circuit for a Cochlear Implant ${ }^{(16)}$

\subsection{Proposed Telemetry Circuit for a Cochlear Implant}

To achieve the desired characteristics of low cost, small size, low power implants, conventional CMOS implants are implemented with 20nm FINFET Technology ${ }^{(23-25)}$. In this regard, respect RF clock generator, Monostable multi-vibrator, PPSK demodulator are designed and implemented to meet the requirement of the proposed model.

\subsubsection{Monostable Multi-vibrator:}

In the implant design, a Monostable multi-vibrator is used as the timer to produce the data rate in user-specified time. The proposed circuit is designed with driving large capacitive loads which are implemented using NMOS technology with less delay, a number of stages, and the width value as shown in Figure 7. NMOS inverters are used to amplify the speed and also reduce the transistor count. The two circuits' (M1 and M2) parametric values are the same, but the difference in capacitance $\mathrm{C} 1$ (1:5) and the chirality value of width (2). Transistor level implementation of Monostable Circuit is shown in Figure 8 


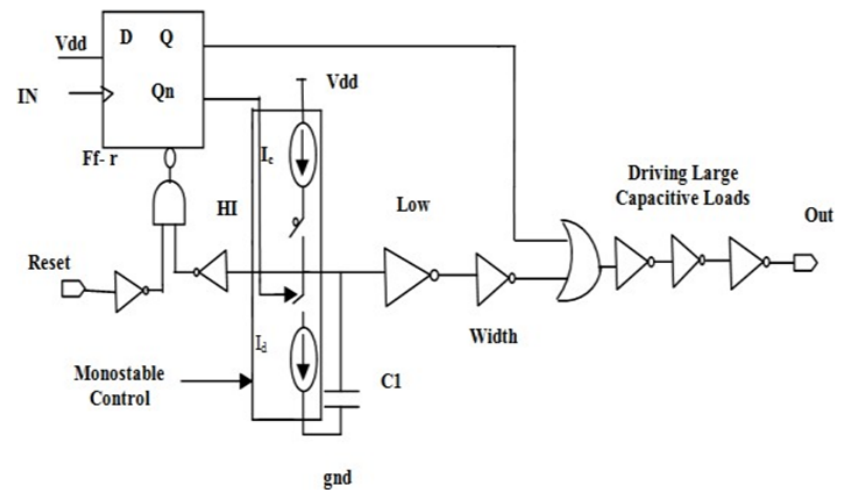

Fig 7. Block Diagram of monostable circuits M1 and M2.

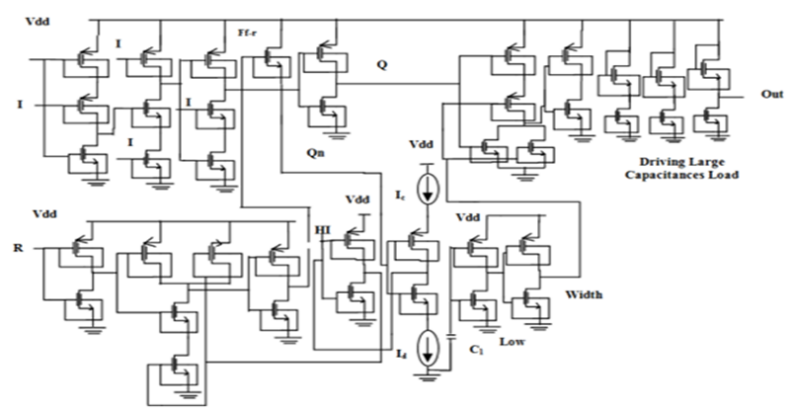

Fig 8. Realization of monostable circuit using FINFET Technology

\subsubsection{PPSK Demodulator:}

At the external transmitter side, the PPSK demodulator is considered. Comparing with the other modulation techniques the efficient way for authorizing data is done by using PSK ${ }^{(26)}$. In the proposed circuit an active low pass filter in place of the comparator is used to achieve good modulation by dragging sufficient power to amplify the output signal with low noise as shown in Figure 9. The first-order low pass filter is driven by resistor $\mathrm{R}$ and Capacitor $\mathrm{C}$ it only allows low-frequency signals but attenuates the signals beyond the cutoff range. As the sine wave response is applied and it generates the triangular wave output by varying $C$ either by charging or by discharging, hence it acts as an Integrator. Chosen $R, C(\tau)$ values are greater than the input time period.

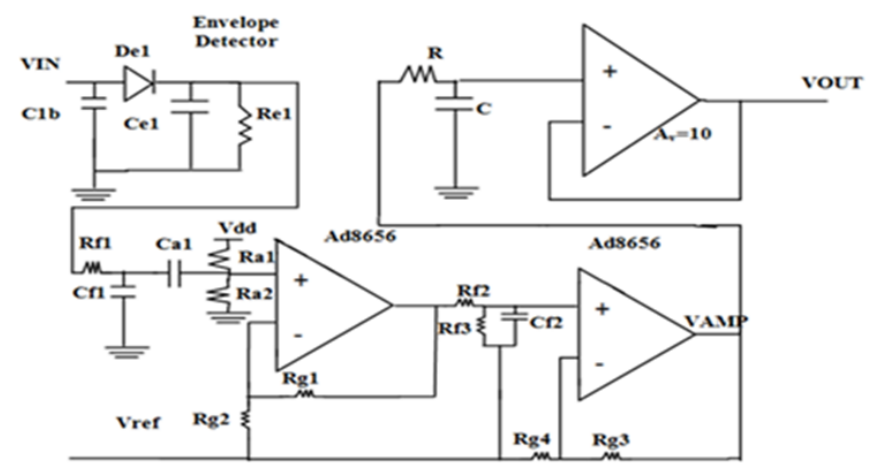

Fig 9. Architecture of Active Low Pass Filter PPSK Demodulator. 


\subsubsection{Calculation for Bit Error Rate (BER) of Monostable Circuit:}

For example, of the generated output of the Monostable circuit, the change of a number of bits of transmitted input (IN) $12 \mathrm{Kbits}$ to receive output bits with an error of 4 bits (VOUT) is defined as BER. So error bits are four divided by $12 \mathrm{~K}$ transmitted bits. The error rate is 0.0000333 .

\section{Simulation Results}

\subsection{Monostable Circuits}

The simulated waveform for M1 and M2 circuits is generated by FINFET $20 \mathrm{~nm}$ technology using the cadence tool by applying $0.4 \mathrm{v}$. As per the transient analysis, the settling time is considered as $7 \mathrm{~ns}$ for data transmission consequently, the frequency range is of $14 \mathrm{MHz}$ Table 1 . The delay, dynamic power dissipation is calculated as shown in Table 2. From the waveform, the capacitor $\mathrm{C} 1$ alters when FF-reset changes from 1 to 0 and Width from 0 to1, with reference to the time axis, the generated output is amplified in accordance with the width and $\mathrm{C} 1$, and it is evident for the less propagation delay in signal transmission from the obtained results of Figure 10.

Table 2. Features Summary

\begin{tabular}{ll}
\hline Technology & FINFET 20nm \\
\hline Design Tool & CADENCE \\
Supply Voltage & $0.4 \mathrm{v}$ \\
Telemetry Specifications & UPLINK \\
Monostable frequency range & $14 \mathrm{MHz}$ \\
Programmable & Implemented using \\
Monostable Circuits (M1,M2) & Driving Large Capacitive Loads \\
Monostable Bit Error Rate & 0.0000333 \\
Uplink Modulation & PPSK using Low pass filter \\
\hline
\end{tabular}

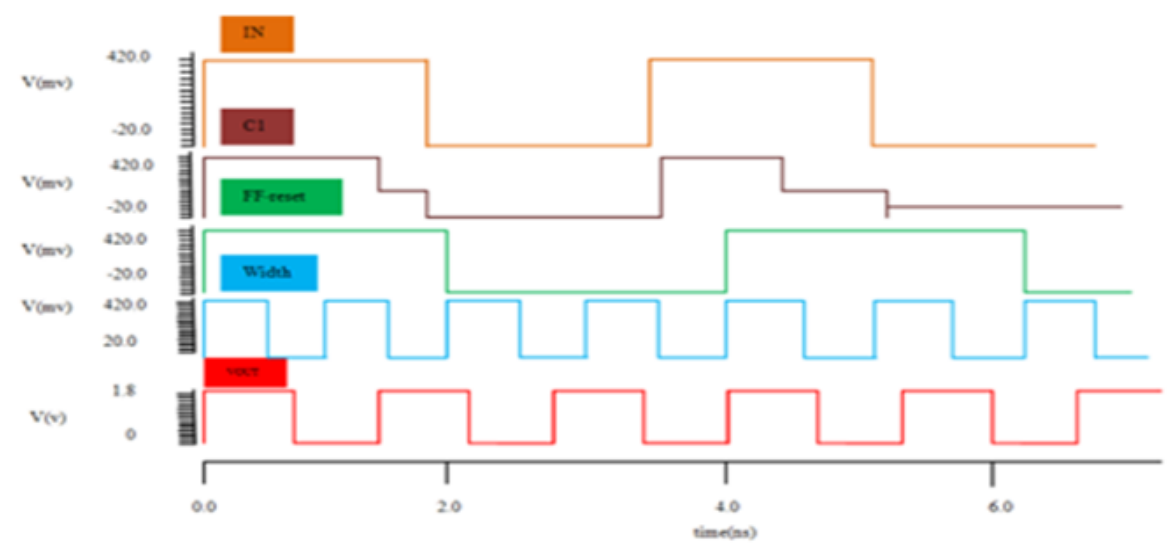

Fig 10. Transisent response of monostable (m1, m2) circuits

\subsection{PPSK Demodulator:}

PPSK demodulator is implemented with $0.4 \mathrm{v}$ supply voltage in $20 \mathrm{~nm}$ FINFET technology here VIN, VAMP, a low pass filter capacitor $\mathrm{C}$ are the inputs, and VOUT is the output. The simulation results are shown below. It is observed in Figure 11. VOUT is dependent on the $\mathrm{C}$ which remains constant until capacitor charges and discharges and changes its phase of the next cycle (VIN) and specifications are tabulated in Table. II, III. Finally, the findings in the paper ${ }^{(27)}$ are more suitable for the design of a demodulator majorly considerable for biomedical implant application. 


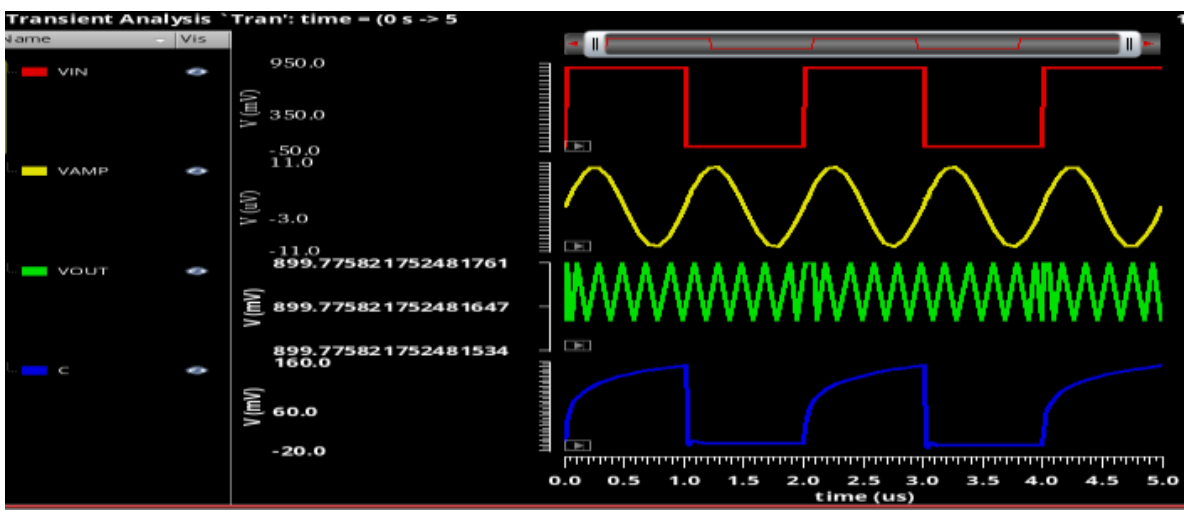

Fig 11. Transient Analysis of PPSK Demodulator

Table 3. Parameters Comparison

\begin{tabular}{lllll}
\hline Design & Delay(ns) & Dynamic Power Dissipation $(\mu \mathrm{W})$ & $\begin{array}{l}\text { Power Delay } \\
\text { PDP }(\mathrm{j})\end{array}$ & $\begin{array}{c}\text { Product } \\
\text { Current Consump- } \\
\text { tion }(\mathrm{A})\end{array}$ \\
\hline $\begin{array}{l}\text { CMOS } \\
\text { Monostable Circuit }\end{array}$ & 116.3 & 8.29 & $0.096 \mathrm{p}$ & $1.26 \mathrm{~m}$ \\
$\begin{array}{l}\text { FINFET } \\
\text { Monostable Circuit }\end{array}$ & 3.3825 & 5.38 & $0.018 \mathrm{p}$ & $0.81 \mu$ \\
\hline
\end{tabular}

\section{Conclusion}

In this paper, Monostable and RF Clock Generator are implemented for cochlear implant application in 20nm FINFET Technology. The existing comparator is replaced by an Active Low pass filter to achieve high accuracy. The conventional monostable circuit is reinstated with driving large capacitive loads to reduce complexity. It is observed that the performance of the proposed design is improved to a large extent, with reduced delay to $34.38 \%$ and power dissipation to $1.54 \%$ with respect to the conventional methods in CMOS. Hence, by using this advanced FINFET technology the performance is increased by $30 \%$.

\section{Author Contributions}

Yatavakilla Amarendra Nath prepared the research methodology and idea for comparative study. All the simulations design, study, and manuscript preparation are done by Hima Bindu Katikala who was assisted by both G.Ramana Murthy and Yatavakilla Amarendra Nath. Result analysis and manuscript proofreading are verified by Professor G.Ramana Murthy.

\section{Acknowledgement}

The authors sincerely thank the Department of Electronics and Communication Engineering, VFSTR, Andhra Pradesh, India for providing the support to conduct the experimental work. This paper is in Research Square Preprint with DOI: https://doi. org/10.21203/rs.3.rs-370782/v1 and It is author's own work, not yet published in any other journal.

\section{References}

1) Al-Haddad K. A modified wireless power transfer system for medical implants. Energies. 2019;12(10):1-21. Available from: https://doi.org/10.3390/ en12101890.

2) Haumann S, Bauernfeind G, Teschner MJ, Schierholz I, Bleichner MG, Büchner A, et al. Epidural recordings in cochlear implant users. Journal of Neural Engineering. 2019;16(5):056008-056008. Available from: https://dx.doi.org/10.1088/1741-2552/able80.

3) Xiu L. Time Moore: Exploiting Moore's Law From The Perspective of Time. IEEE Solid-State Circuits Magazine. 2019;11(1):39-55. Available from: https://dx.doi.org/10.1109/mssc.2018.2882285.

4) Pal RS, Sharma S, Dasgupta S. Recent trend of FinFET devices and its challenges: A review. 2017 Conference on Emerging Devices and Smart Systems (ICEDSS). 2017;p. 150-154. doi:10.1109/ICEDSS.2017.8073675.

5) Ulusan H, Chamanian S, Ilik B, Muhtaroglu A, Kulah H. Fully Implantable Cochlear Implant Interface Electronics With 51.2-uW Front-End Circuit. IEEE Transactions on Very Large Scale Integration (VLSI) Systems. 2019;27(7):1504-1512. Available from: https://dx.doi.org/10.1109/tvlsi.2019.2898873.

6) Hussong A, Rau TS, Ortmaier T, Heimann B, Lenarz T, Majdani O. An automated insertion tool for cochlear implants: another step towards atraumatic cochlear implant surgery. International Journal of Computer Assisted Radiology and Surgery. 2010;5(2):163-171. Available from: https://dx.doi.org/10. 
1007/s11548-009-0368-0.

7) Schurzig D, Timm ME, Majdani O, Lenarz T, Rau TS. The Use of Clinically Measurable Cochlear Parameters in Cochlear Implant Surgery as Indicators for Size, Shape, and Orientation of the Scala Tympani. Ear \& Hearing. 2021;42(4):1034-1041. Available from: https://dx.doi.org/10.1097/ aud.0000000000000998.

8) Zwolan TA. Recent Advances in Cochlear Implants. Contemporary Issues in Communication Science and Disorders. 2008;35(Fall):113-121. Available from: https://dx.doi.org/10.1044/cicsd_35_f_113.

9) Zeng FG, Rebscher S, Harrison W, Sun X, Feng H. Cochlear Implants: System Design, Integration, and Evaluation. IEEE Reviews in Biomedical Engineering. 2008;1:115-142. Available from: https://dx.doi.org/10.1109/rbme.2008.2008250.

10) Bindu K, Rani NU. A Low Power High Efficient Radio Frequency Clock Generator for Bio-Implant. IEEE 2nd International Conference on Communication and Electronics Systems ICCES. 2017. doi:10.1109/CESYS.2017.8321300.

11) Intzes I, Meng H, Cosmas JP. High Data Rate FinFET On-Off Keying Transmitter for Wireless Capsule Endoscopy. VLSI Design. 2018;2018:1-7. Available from: https://dx.doi.org/10.1155/2018/1757903.

12) Gu Y, Aissa S. RF-Based Energy Harvesting in Decode-and-Forward Relaying Systems: Ergodic and Outage Capacities. IEEE Transactions on Wireless Communications. 2015;14(11):6425-6434. Available from: https://dx.doi.org/10.1109/twc.2015.2453418.

13) Taalla RV, Arefin MS, Kaynak A, Kouzani AZ. A Review on Miniaturized Ultrasonic Wireless Power Transfer to Implantable Medical Devices. IEEE Access. 2019;7(7):2092-2106. Available from: https://dx.doi.org/10.1109/access.2018.2886780.

14) Sawan $\mathrm{M}, \mathrm{Hu}$ Y, Coulombe J. Wireless smart implants dedicated to multichannel monitoring and microstimulation. IEEE Circuits and Systems Magazine. 2005;5(1):21-39. Available from: https://dx.doi.org/10.1109/mcas.2005.1405898.

15) Omisakin A, Mestrom RMC, Bentum MJ. Low-Power Wireless Data Transfer System for Stimulation in an Intracortical Visual Prosthesis. Sensors. 2021;21(3):735-735. Available from: https://dx.doi.org/10.3390/s21030735.

16) Jiang D, Cirmirakis D, Schormans M, Perkins TA, Donaldson N, Demosthenous A. An Integrated Passive Phase-Shift Keying Modulator for Biomedical Implants With Power Telemetry Over a Single Inductive Link. IEEE Transactions on Biomedical Circuits and Systems. 2017;11(1):64-77. Available from: https://dx.doi.org/10.1109/tbcas.2016.2580513.

17) Wang G, Liu W, Sivaprakasam M, Kendir GA. Design Analysis of an Adaptive Transconductance Power Telemetry for Biomedical Implant. IEEE Transaction on Circuits and Systems. 2005;52:2109-2117. doi:10.1109/TCSI.2005.852923.

18) Mohseni P, Najafi K, Eliades SJ, Wang X. Wireless multichannel biopotential recording using an integrated FM telemetry circuit. IEEE Transactions on Neural Systems and Rehabilitation Engineering. 2005;13(3):263-271. Available from: https://dx.doi.org/10.1109/tnsre.2005.853625.

19) Eitan N, Shauly. A Review on CMOS Leakage and Power Reduction Transistors and Circuits: Process and Layout Considerations. Journal of Low Power Electronics and Application. 2012;2:1-29. doi:10.3390/jlpea2010001.

20) Hannan MA, Mutashar S, Samad SA, Hussain A. Energy harvesting for the implantable biomedical devices: issues and challenges. BioMedical Engineering OnLine. 2014;13(1):1-23. Available from: https://dx.doi.org/10.1186/1475-925x-13-79.

21) Nair V, Choi J. An Integrated Chip High-Voltage Power Receiver for Wireless Biomedical Implants. Energies. 2015;8(6):5467-5487. Available from: https://dx.doi.org/10.3390/en8065467.

22) Hannan MA, Abbas SM, Samad SA, Hussain A. Modulation Techniques for Biomedical Implanted Devices and Their Challenges. Sensors. 2011;12(1):297319. Available from: https://dx.doi.org/10.3390/s120100297.

23) Blaauw D, Zhai B. Energy Efficient Design for Subthreshold Supply Voltage Operation. 2006 IEEE International Symposium on Circuits and Systems. 2006;p. 4-32. doi:10.1109/ISCAS.2006.1692514.

24) Andreasdemosthenous. Review Article on Advances in Microelectronics for Implantable Medical Devices. Hindwai-Advances in Electronics. $2014 ; 21$. doi:10.1155/2014/981295.

25) Bowonder A, Patel P. Article on Subthershold FINFET for Low Power Circuit Operation. Journal of LowPower Electronics and Application. 2012;2:101-113.

26) Ghovanloo M, Najafi K. A Wideband Frequency-Shift Keying Wireless Link for Inductively Powered Biomedical Implants. IEEE Transactions on Circuits and Systems I: Regular Papers. 2004;51(12):2374-2383. Available from: https://dx.doi.org/10.1109/tcsi.2004.838144.

27) Katikala HB, Murthy GR, Nath YA. Design and Implementation of High Performance PPSK demodulator in Biomedical Implant. Research Square. 2021. Available from: DOI:10.21203/rs.3.rs-370782/v1. 